\section{Ebola: Working through fear}

\author{
Brenda Fitzgerald, MD ${ }^{1}$ \\ ${ }^{1}$ Commissoner, Georgia Department of Public Health
}

It started in Atlanta on August 2, 2014. The first Ebola patient was evacuated from Liberia to Emory University Hospital. Kent Brantly - the first American Ebola patient on U.S. soil - dressed in a hooded biocontainment suit, was met by hospital staff in personal protective equipment (PPE). It was a sobering sight for those watching the media coverage of his arrival.

Three days later, Nancy Writbol, the second American Ebola patient to arrive in the U.S., was taken to the specialized isolation unit at Emory. Writbol was too weak to walk and was wheeled into the hospital wearing a biocontainment suit. Hospital staff were in what was referred to as "bee suits" to protect them from this deadly disease.

From West Africa, where Ebola was spreading out of control, Ebola was arriving in our own backyard in Atlanta, and with it came the fears: Will it spread? Can I catch it? Should I transfer my recuperating aunt to another hospital where they don't have Ebola?

Then on September 30 in Dallas, Thomas Duncan became the first person diagnosed with Ebola in the U.S. Duncan potentially exposed at least 100 individuals to Ebola before he was hospitalized at Dallas Presbyterian Hospital, where he died on October 8, 2015. Two nurses who treated Duncan were the next Ebola victims.

With every newly diagnosed case, with every new symptom, with every plane arriving from West Africa, with every healthcare or aid worker returning with Ebola, the fear and frustration grew. Cries to close our borders were heard from Washington, D.C. to Washington State.

Hysteria grew, fueled by speculation and bad information. The world was on alert as more and more patients were evacuated from the Ebola-stricken countries and sent to hospitals around the world for life-saving care. Pets were quarantined when their owners became sick. Some pets were monitored, others were euthanized.

Health workers in full protective gear boarded planes because some passenger, perhaps, was suffering from Ebola - after all, a few had a fever and diarrhea. That was Ebola, right? No, they hadn't been to West Africa, but they had visited their grandmother in Iowa. Children were being kept out of school for fear of a teacher whose father who worked for the Centers for Disease Control and Prevention (CDC) and had just returned from Guinea, although he was perfectly healthy and had not been near an infected Ebola patient. Even inmates - one in Cobb County- caught on to the hype and the fear the mere mention of the word Ebola

gapha www.jgpha.com caused. He put it to the test, telling the intake nurse he had recently returned from West Africa, he had a fever, and he was throwing up. By the way, he'd been picked up for DUI hours earlier. Although he had no passport and had never been out of the country, for nearly 24 hours he had hundreds of people scrambling and the media were frantic.

Ebola was compared to ISIS. Ebola was coming. Ebola was here! Ebola was going to kill us all! The fiction and distorted truths about Ebola were spreading faster than the disease itself - and farther.

When the Department of Public Health (DPH) transitioned into a stand-alone department in 2011, I wanted to focus on transforming the department into one with increased efficiency and quality. So DPH began applying concepts from "Good to Great," a book by author Jim Collins on the characteristics that make some organizations shine while others maintain the status quo or fail. At the heart of the "Good to Great" framework is recognizing your core values and sticking to what you do best. In our world of Public Health that meant informing the public, preventing disease and protecting health. That is our goal for the department and that was our mission for meeting the challenges of Ebola.

In regard to Ebola, among many things, DPH was charged with communication and information. The public needed to know and understand how Ebola was spread, who was at risk, what the symptoms were, and what should they do if they were sick. Letters were sent to schools, to colleges and universities, and to churches. The DPH website became a source for Ebola information, constantly being updated with the changing recommendations from the CDC. Anyone individuals, health care professionals, educators, and travelers - could call Public Health directly for answers to Ebola questions.

Governor Nathan Deal established an Ebola Response Team to assess state health and emergency management procedures and to produce necessary recommendations to minimize any potential impact of the disease in Georgia. The team was comprised of representatives from the Georgia Emergency Management Agency; the Georgia Department of Public Health; the Georgia National Guard; Emory University Hospital; infectious disease experts in the University System of Georgia; Hartsfield-Jackson Atlanta International Airport; the city of Atlanta; and members of the nursing, rural hospital emergency medical technician, and education communities.

Emory University Hospital had a perfect record for treating Ebola patients. For years, they had trained for a situation 
like this. They had the staff; they had the special containment units; they were ready to handle the next two patients brought to them-but only the next TWO patients. But what if there were more? What if there weren't enough beds and staff at Emory? Where would patients go then?

There was a distinct possibility there would be more especially since the CDC is located in Atlanta. Further, Hartsfield Jackson was one of five airports in the country designated as an entry point for individuals coming from West Africa.

The first step was to establish a monitoring system for every traveler coming from Liberia, Guinea, or Sierra Leone. They were questioned about their health before boarding their flight out of West Africa and questioned again when they landed. Each was given a kit containing a thermometer and instructions on taking their temperature and monitoring for any possible symptoms of Ebola. They were instructed how to $\log$ their information and report it to DPH.

Using a system already in place for tracking and recording other infectious diseases in Georgia, DPH created an online monitoring portal for travelers with possible exposure to Ebola. Travelers were given login instructions and based on their level of risk; they took their temperatures daily and recorded the results by logging into the system. For those who were not computer literate, they could email their information or simply call DPH. Some individuals required face-to-face monitoring, which could be accomplished via Skype, Face Time or home visits. Everyone entering the country through Atlanta was required to monitor and selfquarantine as necessary. On at least two occasions, that included the head of the CDC. For those who might refuse, there was at the Fulton County Jail, but it was never needed. Hospitals and emergency medical services (EMS) needed to know what to look for, what questions to ask, and how to handle patients with possible exposure to Ebola. They needed guidelines for isolating and diagnosing, and they needed personal protective equipment (PPE). Pocket-sized cards with information ranging from infection control to intubation of a potential Ebola patient were developed and distributed to all EMS.

A three-tiered system was developed for dealing with Ebola. All hospitals in Georgia were considered tier-three hospitals. They were to identify patients at risk for Ebola, taking into consideration travel history and symptoms and to isolate them as needed. Tier-two hospitals had the capability of managing a suspect case of Ebola - including specimen collection for diagnostic testing and laboratory capacity for diagnosing. Tier-one hospitals were those for treatment of patients with Ebola. These hospitals were required to have facilities and procedures suitable to treat Ebola, including isolation areas, laboratory capacity, strict infection control procedures, appropriate staff, and PPE. These specifications often required time for implementation. Some hospitals had to make physical changes, and acquire proper equipment and PPE, and generally, staff had to undergo intense training. Once that was accomplished, they were reviewed by the CDC and the DPH and designated as treatment facilities. Georgia now has five treatment hospitals and eight diagnosing hospitals, with one more to be designated in the coming weeks.

Since suspect Ebola patients would need to be moved between hospital facilities. EMS companies in 25 areas throughout Georgia were designated for transport. These companies now have PPE, advanced protocols, and increased training. All EMS transports of potential Ebola patients would be monitored through a dedicated phone line providing triage, along with EMS coordination and dispatch.

Initially, only the CDC could perform testing for Ebola. As the number of Ebola tests increased, DPH sought and received certification for the Laboratory Response Network of the State Public Health Laboratory to perform Ebola tests. The laboratory purchased Bio Fire testing equipment, and arrangements were put in place for the Georgia State Patrol to transport specimens for testing. For assessment hospitals that could not perform routine blood testing because of the infection control requirements, Grady Memorial Hospital agreed to conduct those tests.

To date, DPH has monitored 1,123 travelers with risk of exposure to Ebola. Of that number, 26 have been medically evaluated. Five individuals were tested for Ebola; all of those tests were negative. Monitoring of travelers continues today and likely will continue through the end of the year.

Ebola is still with us, and the next disease like it is somewhere in the world. I am very proud of DPH's accomplishments. We don't have just a good plan and system - we have a GREAT plan and system in place for meeting Ebola and similar diseases should it become necessary. It is a plan and system that can be used for any unforeseen - at least for now - infectious disease outbreak.

\section{Inform. Prevent. Protect.}

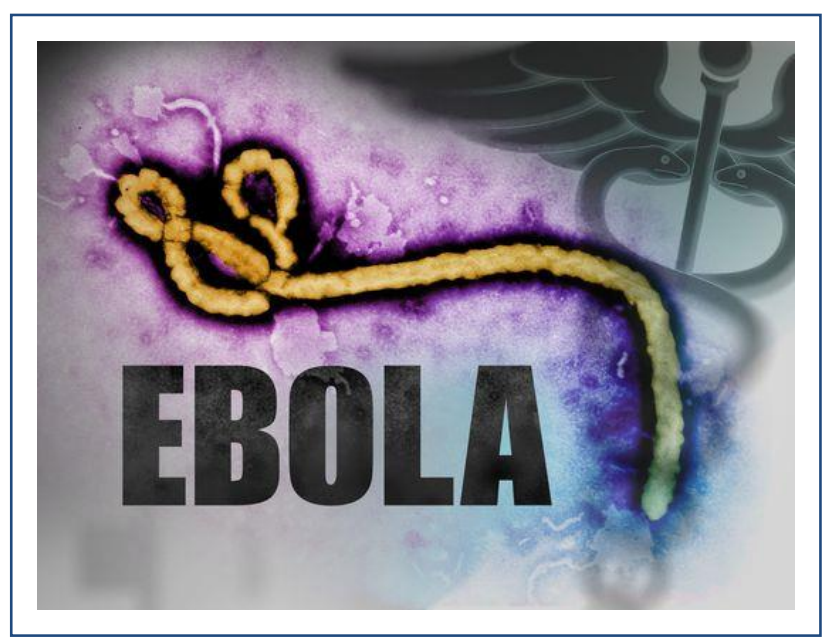

